Send your letters to the Editor, British Dental

Journal, 64 Wimpole Street, London W1G 8YS

E-mail bdj@bda-dentistry.org.uk

Priority will be given to letters less than 500

words long. Authors must sign the letter,

which may be edited for reasons of space.

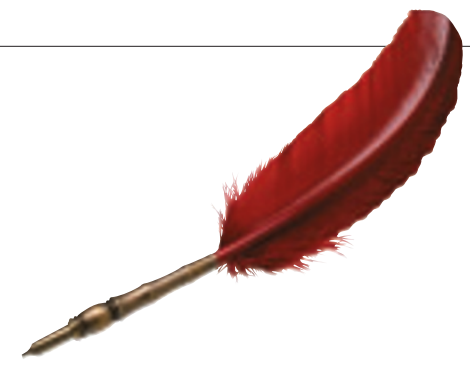

shown that while patients have difficulty rating practitioners' technical ability they offer a unique perspective for rating their dentist's interpersonal skills. NHS Education for Scotland is currently considering the use of a new patient assessment questionnaire (PAQ) for evaluating dentists' professionalism and communication skills as one element of a proposed national system of assessment for VT and GPT.

Questions contained in the PAQ take into account the recommendations and priorities of stakeholders including the public, the profession and relevant governing bodies, incorporating principles defined in GDC and NHS publications and research findings on patient needs in dentistry.

Questions were representative of training objectives in communication and professionalism domains described in the Scottish VT/GPT competency document. The PAQ also requested patient demographic information to determine whether data was subject to patient-bias. Feedback was generated in the form of a mean patient rating per item and a patient rating frequency per item. Demographic information on participating patients is also available to trainees on request.

The PAQ was the subject of a small-scale pilot study conducted within the GDS last year. Preliminary results show the PAQ to fulfil the criteria required for robust assessment - those of reliability, validity and feasibility. The generalizability coefficient calculated from the pilot study data has an average value of 0.84 across the PAQ items provided a minimum of 20 questionnaires is returned per trainee. This level of reliability is generally accepted as sufficient to rank individuals if required. No evidence was found for significant patient bias when rating dentists using the PAQ. Internal consistency calculations showed moderate correlation (Pearson's correlation coefficient 0.5-0.7) between items indicating that different aspects of the same attribute are being tapped by the PAQ. Trainees participating in the initial pilot study and their trainers were surveyed to investigate the feasibility and value of PAQ in practice. Results were encouraging with 80 per cent of respondents reporting that they found feedback useful and 38 per cent likely to change the way in which they practice as a result of feedback.

A second draft of the PAQ is currently being piloted on a larger scale throughout Scotland alongside the other elements of the assessment system. This should provide the necessary data set to enable thorough evaluation of the PAQ as an assessment instrument and possibly pave the way for its use within other dental services and arenas. Development of the system of assessment for VT/GPT (which includes the PAQ) is funded by NHS Education for Scotland.
Y. Hurst
L. Prescott
J. Rennie
Edinburgh

\section{Patients not customers}

Sir,- The Office of fair trading report into private dentistry contains some excellent suggestions, the implementation of which should, in broad terms, serve the public interest well. However, one aspect requires very close examination before it is allowed to pass.

The press release from the OFT refers to dental patients as customers. The $B D J$ has recently hosted correspondence related to the ethical marketing and selling of dental procedures. Columns are related to the 'business of dentistry'. Nevertheless, the financial constraints on public support for provision of dentistry and the OFT examination of the alternative should not cloud the central issue. Dentists are not retailers. They have a professional responsibility for the standard of care and advice offered and unlimited professional liability.

Dentists do not leave, or choose to practice outside the NHS, because they are greedy individuals looking for vast incomes. They make that decision on the basis of the need to be comfortable with a system of professional ethics. They are aware of an exponential growth of 
litigation against them: litigation which is often generated because they have tried to provide the best care they can in limited time available, only to find that both ethically and legally, lack of time is not a justification for compromise to the standard of care provided.

The OFT has been excited by the cost differential between NHS and private fees. Many individual dentists, specialist societies and organisations have campaigned for years about the pressure on the standards of care that the terms of service available through the NHS imply. The OFT now wishes to introduce an effective system for the monitoring and enforcement of standards in private dentistry. Had there been an effective system for monitoring and enforcing the standard of care delivered through the NHS, then successive governments would have been publicly embarrassed by the woeful under-funding of NHS dentistry. As it is, even the rudimentary controls exercised by the DPB through the DROs are scheduled for the scrap-heap under 04C. There is no rule more simple, either for the retailer or for the customer, than 'You get what you pay for'.

If the election not to practice under the terms of the Health Service is to be pursued by the OFT on the basis of restricting the flexibility to charge a particular fee for a particular service for a particular patient in particular circumstances, it will represent a constraint on the patient to choose to buy the amount of time that an ethical practitioner believes to be necessary to provide a high standard of care.

The glowing reference made by the OFT to terms of service in Holland is particularly interesting in this respect. Private fees are capped in Holland. There is very little scope for variation, irrespective of the variation either in the degree of clinical challenge or in the skill and experience of the operator. There is complexity and diversity in any biological system. Fees scales need to be flexible in order to reflect that variability.

No one could dispute that a patient is entitled to information in advance about the availability or cost of consultations and treatment. Thereafter the decision is up to the patient. It is 'social engineering' of the most patronising and invasive sort to seek to control that professional relationship.

The dentist is a professional and most of us believe that that is greatly in the best interest of the public. Any change in the terms of service which conflicts with or diminishes that professional ethic will not be in the long term interest of patients.

A. T. Hyatt

London

\section{Dental nurse registration with GDC}

Sir,- I write in response to Mr Arthur Cooper's letter (BDJ2003; 194: 233).

The GDC has consulted widely on its proposals to regulate the dental team (including dental nurses) and on its curricula framework for Professionals Complementary to Dentistry (PCDs). Every registrant has been contacted directly via our publication the GDC Gazette, full details have been available on our web site, and we have sought comments from key organisations representing the dental team stakeholders, including the BDA, and consumer groups. The responses to each of the points raised by Mr.Cooper are as follows. Our web site (http://www.gdcuk.org/pcds.html) contains further details of the PCD reform programme, and any follow up queries are welcome to me at the contact points provided at the foot of this letter.

1. Only registered dental nurses will be permitted to operate at the chairside. This is not the case. The GDC proposes that both registered dental nurses and dental nurses in recognised training will be permitted to work at chairside. Those permitted to register during a two-year transitional period will include both qualified dental nurses and dental nurses who are experienced but unqualified.

2. In emergencies will dentists be restricted to working with registered dental nurses? In an emergency dentists should take the action which in their professional opinion is in the patient's best interests, given the circumstances in which they find themselves. There may be emergencies in which the use of non-registered personnel is required to prevent serious harm to a patient: if so, a dentist would be entitled to use this in defence of his or her actions. (However, it should be noted that, in respect of the statutory offence of illegal practice, no general 'emergency' defence exists - this is already the case under the current system.)

3. With whom will dentists be able to work if their registered dental nurse or dental nurse in training is ill or absent due to professional study requirements?

Dentists will be expected to ensure that properly trained and registered staff are available to provide necessary care. This is no different from other areas of healthcare.

4. In rural areas where no college-provided dental nurse training is available nearby, dentists will have to fully train their nurses themselves. This will require that they close their practice to do so.

The Council is working with dental nurse training providers to promote effective, accessible, work based (rather than college based) dental nurse training across the UK. There are examples of practices in rural areas that are grouping together to provide dental nurse training on site which minimises the need to close a practice. GDPs facing such problems are urged to consult their local deaneries and Workforce Development Confederations.

5. Some dental nurses are very competent practitioners but do not have a natural aptitude for exams. These nurses will be lost to the profession under the GDC proposals

The work-based National Vocational Qualification (NVQ), is largely awarded on the basis of on-the-job assessment. It is hoped that this qualification will assist these candidates. Existing experienced dental nurses will be eligible to apply for registration under a 'grandparenting' route which will be available for a period of two years from the date of first opening of the PCD register (expected in 2004).

6. Compulsory registration of dental nurses and restriction of the use of nonregistered staff at the chairside could severely compromise the patient care that the GDC is supposed to protect.

Public protection has been the first and foremost consideration in developing the Council's regulatory proposals for the dental team, which have been the subject of public debate and refinement for many years. Registration of dental nurses (as for all other team members) is proposed according to explicit role criteria (defined by a curriculum framework and ethical guidance). The Council considers that this basis of registration will greatly enhance public protection across the breadth of dental service provision.

$B D J$ readers are encouraged to send any queries to rcliffordgdc-uk.org or to phone 02078873853.

\section{R. Clifford}

General Dental Council London

\section{Acidic $\mathrm{pH}$ of water}

Sir,- I read with interest D.S. Wilsons' letter (BDJ 2002; 194: 181) regarding the acidic $\mathrm{pH}$ of filtered tap water. Although I haven't seen any patient yet with tooth erosion caused by this, I must say that I have tasted filtered water myself and it did taste acidic immediately after changing the Brita cartridge (I have followed their instructions). The acidic taste disappeared after using the cartridge for a few days.

\section{B. Hikmat}

London 